\title{
加强项目建设 解决灌区存在问题
}

赵兴海

陕西省渭南市东雷抽黄灌溉工程管理局

DOI:10.32629/hwr.v3i3.2006

[摘 要] 原站作为灌溉和涝区排水工程的重要工程, 关系着整个灌区是否能够正常运转。并且原站工程的高效运行对于提高 灌区效益具有重要意义,但是基于各种因素的影响,使其存在诸多问题,基于此,本文阐述了工程概况及存在问题,对原站改造及 其改造效果进行了探讨分析, 旨在保障原站工程高效运行。

[关键词] 原站工程; 问题; 改造; 效果

原站工程能够辅助水利工程进行水资源调节, 确保水利 工程使用效益。但是由于厤站工程运行过程中受到诸多因素 影响, 因此为了保障百站工程的有效运行, 以下就洜站工程 问题及其解决进行了探讨分析。

\section{1 工程概况及存在问题}

东雷抽黄大型灌溉泵站工程是陕西省关中东部利用黄 河水源修建的多级高扬程大型电力提灌工程, 惠泽合阳、大 荔、澄城、蒲城四县 13 个乡镇 47 万人民。该工程属大 (I) 型泵站工程, 设计灌溉面积 102 万亩, 共建各类抽水百站 28 座, 安装水洜机组 133 台 (套), 总装机功率 11.86 万千瓦, 设 计流量 60 立方米/秒, 最多 9 级提水, 单级最高扬程 215 米, 累计最高扬程 311 米, 加权平均扬程 170 米。

该工程于上世纪七十年代后期设计并建成收益, 机电设备 在当时条件下属于 “高、大、新” 设备, 但自投入运行后, 问题 很多, 给运行管理带来了很大的困难和挑战。主要表现在:

1.1 泥沙对水百过流部件的磨蚀。黄河水为高泥沙含量 水质, 最高含沙量 $137 \mathrm{~kg} / \mathrm{m}^{3}$, 平均含沙量 $31 \mathrm{~kg} / \mathrm{m}^{3}$, 且夹杂大 量的石英石、长石及铁矿石等物质, 造成水泵过流部件严重 磨蚀。东雷一级站 $16 \mathrm{CJ}$ - 80 型轴流泵运行约 400 小时, 泵轴 下导处 4 毫米不锈钢轴套即被完全磨损, 水泵剧烈震动, 不 能运行。东雷、新民、南乌牛三个二级站安装的 H2、H3、 H4 系列黄河试制离心原, 叶轮在运行约 500 小时后出现蜂窝 麻面, 运行 800 1000 小时则叶片磨蚀穿孔, 近乎报废, 洜体 磨蚀严重, 出现蜂窝麻面。原上 SH 系列离心原运行约 2000 小时, 叶片出现磨蚀穿孔, 水葲出流严重衰减, 叶轮需更换。

1.2 试制产品多, 安全性差。东雷、新民、南乌牛三个 二级站安装的黄河系列 H2、H3、H4 离心原是沈阳水洜厂专 门为东雷抽黄工程设计制造的离心原, 为试制产品。其中东 雷二级站安装的 H 2 型号为 KD2. 2- $100 * 2$ 的双级单吸离心原, 单机流量 $2.2 \mathrm{~m}^{3} / \mathrm{s}$, 扬程 $220 \mathrm{~m}$, 为亚洲之最。该百为单侧进水, 轴向力大, 推力轴承易损, 高压侧密封极易因磨损而漏水。黄 河系列泵的配套电机为兰州电机厂改制的 TD215/120-8 型 $8000 \mathrm{~kW}$ 同步电动机, 为当时全国泵站单机最大功率, 电机绝 缘性能差, 多次因相间绝缘降低或击穿而检修。三个二级站 出水管道安装的 Z943SA-40 型电动平板闸阀和 D $841 \mathrm{H}-25$
型两阶段关闭电液操纵蝶阀 (缓闭阀) 为沈阳高中压阀门厂 试制产品, 平板闸阀常因卡涩或力矩不够而影响正常开停机, 操作动作极不可靠, 运行安全性差。

1.3 安全运行率较低。受当时设计技术及加工制造技术 的限制, 设备性能差, 故障频出, 致使设备安全运行率较低, 这些问题突出反映在试制设备上。

\section{2 洜站改造,解决问题}

为了克服泥沙因素、试制产品性能问题及技术因素给东 雷抽黄灌区泵站机电设备的运行管理带来的困境, 我局先后 对东雷一级站的 $16 \mathrm{CJ}$ - 80 型轴流原进行加装下导轴承密封 装置技术改进, 泵轴密封筒全密封技术改进, 大幅度延长了 水洜的运行时间。为解决离心原过流部件磨蚀问题, 管理局 成立了抗磨喷涂站, 对水百过流部件表面喷涂防护层进行防 护, 有效延长了叶轮的运行时间。将电动平板闸阀的电动操 纵机构改为液压操纵机构, 提高了启闭的可靠性。通过这些 技术改进及技术措施的采取, 较好地维持了灌区的供水生产, 但还不能彻底解决试制产品性能差、装置效率低的问题。随 着国家大型洜站更新改造项目的实施, 这些困扰洜站设备管 理的问题迎来了解决的机遇。

在泵站更新改造过程中, 管理局明确提出在新材料、新 工艺的应用上要有新作为, 在科研创新上要有新突破, 着力 解决制约灌区发展及泵站管理的问题。主要应用有:

2.1 针对东雷、新民、南乌牛三个大型洜站扬程高、流 量大, 水泵过流部件磨蚀严重的问题, 借鉴其他行业和灌区的 经验, 决定使用 Gr26 高铬白口铸铁制作水泵的叶轮和密封环 进行试验。该材料的洛氏硬度 (HRC) 可达 60 以上, 非常耐磨, 以前广泛应用在渣浆洜上, 东雷二期抽黄的北干二级站和下 寨三级站的立式离心原 (扬程 $70 \mathrm{~m}$ ) 上已应用。目前, 安装在南 乌牛二级站 (扬程 110m) Gr26 叶轮和密封环已运行近 2000 小 时, 磨损量小于 $0.2 \mathrm{~m}$, 耐磨效果非常好, 按此推算, 叶轮寿命可 达 8000 10000 小时, 有效解决了叶轮的磨蚀问题。

2.2 A3 钢板焊接叶轮及其与密封环结合部喷焊 Ni60 合 金粉末技术在系列 SH 原上的应用。叶轮采用耐气蚀的 A3 钢 板热压焊接成型, A3 钢的机械性能优于铸铁, 易加工, 表面光 洁度好, 叶型容易达到设计要求, 且已修复, 在叶轮与密封环 


\section{浅谈工程合同管理的重要性}

尚克琴

新疆下坂地水利枢纽工程建设管理局

DOI:10.32629/hwr.v3i3.1981

[摘 要] 水利工程施工及工程管理的主要部分为工程合同管理。施工合同管理是对施工项目完成情况起关键作用,是工程项 目管理的核心,它始终贯穿于整个工程项目建设的始末。

[关键词] 新疆; 合同管理; 重要性

新疆维吾尔自治区位于亚欧大陆中部祖国边陲, 总面积 166 万平方公里, 大概占全国陆地面积的六分之一。新疆属于 温带大陆性干旱气候, 降水稀少、蒸发强烈, 年均降水量 154.8 毫米。境内山脉融雪形成约河流 570 多条。冰川储量 2.13 万 亿立方米, 有“固体水库”之称。水资源总量 832 亿立方米, 居 全国前列, 但单位面积产水量仅为全国平均的六分之一。水资 源时空分布极不均衡, 资源性和工程性缺水并存。新疆地处干 旱地区, 在新疆, 水利是农业的命脉, 也是国民经济的命脉。

近年新疆大力发展水利基础设施建设领域, 加强水资源 的合理配置, 着力抓好重大引水调水工程和山区水利控制性 骨干工程、流域开发治理工程建设, 先后统筹阿尔塔什水利
枢纽等 5 座大型水库和, 奴尔水库等 17 座中型水库建设, 开 工建设玉龙喀什水利枢纽工程, 推进奥依阿额孜水利枢纽工 程、库尔干水利枢纽工程、莫莫克水利枢纽工程前期工作。 继续实施 27 个大型灌区节水改造建设, 启动南疆 19 个中型 灌区节水改造项目建设。加强重点河流防洪治理、大中型病 险水闸除险加固、重点区域城乡饮水安全等工程建设, 重点 加快 22 个深度贫困县农村饮水安全㺬固提升工程建设。

水利工程施工及工程管理的主要部分为工程合同管理, 施工合同管理是对施工项目完成情况起关键作用, 是工程项 目管理的核心, 它始终贯穿于整个工程项目建设的始末。

\section{1 工程合同管理的重要性}

的结合部及密封环内表面喷焊 Ni60 合金粉末, 利用该合金较 高的硬度 (HRC 在 60 左右), 提高零件关键部位的耐磨性能, 较好地解决了叶轮和密封环出磨损较快的问题, 大幅度提高 了过流部件的使用寿命。

2.3 为了实现在运行状态不停机、不压闸进行水洜流量的 调节, 解决梯级泵站流量调配难的问题, 泵改中在西习五级站 和习家庄七级站分别采用了内馈式变频调速电机和无刷双馈 变频调速电机, 机组转速从 800 980r/min 无级连续调节, 水 泵流量从 $0.3 \sim 0.75 \mathrm{~m}^{3} / \mathrm{s}$ 范围调节, 提高了灌溉配水的灵活性。

2.4 电动半球阀的应用。将东雷、新民、南乌牛三个二 级站的液压平板闸阀改为 QDYQ940-25C 型电动硬密封半球 阀, 此闸阀止水效果好、密封严, 启闭力矩大。通过南乌牛站 几年来的运行效果看, 该闸阀操作安全, 工作可靠。

2.5 利用泵站更新改造的有利时机, 将塬上泵站的出水 断流装置全部更换为节能型侧翻式拍门, 该产品无需启闭装 置, 可自动启闭, 止水效果良好, 开启角度达 $85^{\circ}$, 材料选用优 质铸铁, 维护方便, 使用寿命长。

\section{3 洜改后的效果}

3.1 原站运行的可靠性、安全性提高

我局泵站更新改造实施以来, 19 座泵站的 103 套水泵机 组、电气设备和 17 座 $35 \mathrm{kV}$ 变电站、大部分金属结构得到了 更新, 泵站运行的可靠性、安全性大幅度提高, 所有改造泵站 实现安全可靠运行。2017 年, 完成渠首引水 1.4 亿方, 斗口 引水 1.02 亿方, 创造了灌区斗口引水新纪录。

\section{2 泵站效益提高}

泵改后, 泵站的能源单耗从原改前的 4.65 度/千吨米下 降到 4.0 度/千吨米, 全局斗口单方水用电量从 1.3 度下降到 1.02 度, 年节电 1500 2000 万度, 节约电费 400 万元以上, 泵站效率大幅提高, 效益显著。

3.3 维修成本降低

随着东雷、新民、南乌牛、高明等几个大型泵站更新改 造的完成, 全局机电设备维修费用大幅下降, 改造前年维修 费在 200 万元以上, 改造后年维修费在 130 万元以下, 年节约 维修费用在 70 万元以上, 成本降低明显。

\section{4 结束语}

乘着国家大型灌区泵站更新改造项目的东风, 困扰我局 泵站管理的诸多问题得到有效解决, 泵站运行的安全性、可 靠性大幅提高, 效益显著。随着洜改的完成, 灌区发展已跃上 一个新的平台, 必将为灌区经济的腾飞发挥更大作用。

\section{[参考文献]}

[1]陶玉琴.工农渠灌区大型原站改造后费用增加的原 因及对策措施[J].农业科技与信息,2017,(01):120-121.

[2]盛成军. 从阜宁原站更新改造的实践谈应注意的几项 技术措施[J].江苏水利,2014,(10):11-12.

[3]刘旭东.原站更新改造中的关键技术措施探讨[J]. 价 值工程,2018,37(10):195-197.

[4]荣垂涛,王蕾,张婵婵. 灌区洜站技术更新改造[J].水能 经济,2017,(4):73. 